\title{
Factors Related To Job Satisfaction Among Nurses
}

\author{
Majlinda Zahaj, MD, PhD \\ Aurela Saliaj, MD, PhD, Prof.asoc. \\ Lorina Metani , RN, MSC \\ Sonila Nika, RN, MSc \\ Evis Alushi, RN, MSc \\ Public Health School, University of Vlora, Albania
}

doi: 10.19044/esj.2016.v12n5p100 URL:http://dx.doi.org/10.19044/esj.2016.v12n5p100

\begin{abstract}
Background: The level of job satisfaction affects not only the quality of the function exercised by the nurse, but also patient satisfaction, therefore it is very important for health care institutions to measure these perceptions amongst nurses.

Aim of the study: This research had assessed the job satisfaction among nurses in the Public Hospital Vlora, Albania and the contributing factors on it.

Method: Data of this cross-sectional research were collected using a questionnaire which measures job satisfaction, based on Mueller and McCloskey Satisfaction Scale (MMSS), adapted.

Results: The professional pleasure that nurses sense to their profession is close to neutral $(x=2.92)$, with the trend to dissatisfaction. Most important extrinsic factor that affects the intensity of satisfaction in the nursing profession is 'monthly payment' (4.5 points), while as the most important intrinsic factor is ranked "career escalation" (3.84 points).

Conclusions: In conclusion, we can say that the level of professional satisfaction among nurses involved in this study was below the average. Less satisfied groups from nursing profession were young people and high educated nurses. The low level of professional gratifying is expressed as well in the fact that over $70 \%$ of nurses in the study would like to practice another profession.
\end{abstract}

Keywords: Job satisfaction, monthly salary, professional education, work experience

\section{Introduction}

Satisfaction in exercising a profession has its origin in the motivation 
to work (2-factors theory of Herzberg) (Herzberg Frederick, 1959). Job satisfaction is defined as the difference between expectations about the profession and the actual professional experience. It is a significant indicator of how people feel with their profession, how they meet professional job duties, or otherwise abandons it voluntarily.

According to the Bureau of Labor statistics from 2010 to 2020, the number of nursing professionals is expected to be raised by $26 \%$, partly impacted by the increasing medical needs of an ageing population (Anthony P. Carnevale, 2012) (Mathew, 2015). Anyway, in today's economy, salary and high satisfaction of being a nurse makes the medical field a very good choice for anyone who likes to help others and not a career.

Job satisfaction is an essential element in keeping the workforce of any organization. Lack in professional pleasure not only hinders the pace of work, but also can have adverse effects for the individual, such as the 'burnout' effect (Mrayyan, 2005). Nowadays the number of nurses who are voluntary leaving the profession is increasing, caused by various factors which are being studied more and more (Ahmad H. Abu Raddaha, 2012).

Taking in consideration that the level of job satisfaction affects not only the quality of the functions exercised by the nurse, but also patient satisfaction is very important for health care institutions to measure these perceptions by the nurses. Many studies have identified significant correlations in health care organizations, between staff satisfaction and the patient's one (Knoopa, 2010) (Al-Aameri, 2000).

Working as a nurse gives the opportunity to work in different environments, to have contacts with health professionals and to get fair salaries. Many studies have assessed the level of job satisfaction among them (Wang Haijuan, 2006) (Savič, 2012 ) (Abida Sultana, 2011). They have demonstrated that payment satisfactory, better employment prospects and challenging work, lead to increased job satisfaction as a nurse; also these professionals must be satisfied with the fact that they are helping many human beings. Anyway, more research is required to understand the relative importance of the many identified factors to job satisfaction ( $\mathrm{Lu} \mathrm{H}, 2005)$.

The only one published research about this topic in Albania, points up the fact that there is a lack of focus/research on commitment and job satisfaction studies in public hospital settings in Albania (Gabrani Adriatik, 2014). Considering this recommendation and the fact that the level of job satisfaction directly affects professional nursing performance, this paper will assess the job satisfaction among nurses in the State Hospital Vlora, Albania and the determining factors on it.

\section{Material and method}

This cross-sectional study included 50 nurses employed in 3 wards of 
the State Hospital of Vlora in Albania (surgical, adult care and infectious diseases), during the period January-August 2015. 3 of them refused to be interviewed. They were chosen with random selection among 264 nurses employed in of the Vlora's Public Hospital. The interviews were conducted in the end of shift.

Data were collected using a set of questionnaires that included the questionnaire to measure job satisfaction based on Mueller and McCloskey Satisfaction Scale (MMSS) (Mueller CW, 1990), adapted.

Brief Description of Instrument - Measures nurses' job satisfaction related to work experience and educational level. Determining factors were assessed in 2 main domains: 7 intrinsic factors (autonomy, promotion, carrier growth, responsibility at work, equally treatment, professional opportunities, praise/recognition) and 9 extrinsic factors (extrinsic rewards, interactions, occupational safety ect).

Scale Format - 5-point Likert (5=very satisfied, 3=neither satisfied nor dissatisfied (neutral), 1=very dissatisfied).

Administration Technique - Self-administered questionnaire.

Data processing was done with SPSS, version17. To compare ratios, Pearson's correlation was used. To compare the quantitative variables between two groups, were used the Student's t-test correlation or the non parametric Mann-Whitney correlation. Significance levels were bilateral and the statistical significance was defined on 0.05 .

Ethical issues:

The study was conducted with the permission of the hospital's ethical council. All respondents were provided with complete anonymity, at the time of the interview and during result's publishing as well. The hospital administration was kept out from the whole process and anyone was forced to participate in the questionnaire.

Limitations: The conclusions of this study are limited by the small sample and by the fact that it is conducted only in one public hospital.

\section{Results}

In this study participated 38 female nurses and 12 male ones. The average age of the respondents was 40.6 years $(S D=8.64)$. The $14 \%$ of the respondents had less than 2 years of work experience in of cases, 2-5 years in $14 \%$ of cases, $38 \%$ had 5-10 years of work experience as a nurse and $34 \%$ had more than 10 years of work experience.

The measurement of nursing job satisfaction in different wards was realized through 5 opportunities. Only 6\% of the respondents said they were very disappointed by this profession, 20\% were somewhat satisfied, $44 \%$ were neutral, $20 \%$ of nurses expressed that they were somewhat satisfied, while only 6\% presented very pleased (Table 1). 
Table 1. Demographic data and nurse' s perception on their job

\begin{tabular}{|c|c|c|c|}
\hline & & $\mathbf{N}$ & $\%$ \\
\hline \multirow{2}{*}{ Gender } & Male & 12 & 24 \\
\hline & Female & 38 & 76 \\
\hline \multicolumn{2}{|l|}{ Age, mean \pm SD } & \multicolumn{2}{|c|}{$40.68 \pm 8.64$} \\
\hline \multirow{3}{*}{$\begin{array}{l}\text { Educational } \\
\text { level }\end{array}$} & Bachelor degree & 28 & 56.0 \\
\hline & MSc or MP (in process) & 12 & 24.0 \\
\hline & MSc or MP (completed) & 10 & 20.0 \\
\hline \multirow{4}{*}{$\begin{array}{l}\text { Years of work } \\
\text { experience }\end{array}$} & $>2$ & 7 & 14 \\
\hline & $2-5$ & 7 & 14 \\
\hline & $6-10$ & 19 & 38 \\
\hline & $>10$ & 17 & 34 \\
\hline \multirow{5}{*}{$\begin{array}{ll}\text { Level } & \text { of } \\
\text { satisfaction }\end{array}$} & Very satisfied & 5 & 10 \\
\hline & Somewhat satisfied & 10 & 20 \\
\hline & Neutral & 22 & 44 \\
\hline & Somewhat dissatisfied & 10 & 20 \\
\hline & Very dissatisfied & 3 & 6 \\
\hline \multirow{2}{*}{$\begin{array}{l}\text { Choosing } \\
\text { profession }\end{array}$} & Accidentally & 31 & 62 \\
\hline & Willingly & 19 & 38 \\
\hline \multirow{3}{*}{$\begin{array}{l}\text { Want to change } \\
\text { profession }\end{array}$} & Yes & 7 & 14 \\
\hline & No & 14 & 28 \\
\hline & I would like, but can’t & 29 & 58 \\
\hline
\end{tabular}

Nurses were asked whether their choice to practice as a nurse has been willful or accidental. $62 \%$ of surveyed nurses said that they had forcedly chosen this profession, while $38 \%$ have chosen to become nurse intentionally. $14 \%$ of nurses under the study were seeking for another profession, $8 \%$ wanted to change profession but could not, while $28 \%$ did not want to change profession, because they were satisfied with their role as a nurse.

Satisfaction index was found that at a level of 2.92 ( $\mathrm{SD}=1.027)$, indicating that the satisfaction that nurses perceive toward their profession is close to neutral, with a tendency of discontent.

People who say that feel very unhappy about their job are those who have less than 2 years of work experience as nurses. No one of them stated to be satisfied. Those who say they feel very satisfied with this profession are nurses with more than 10 years work experience.

It can be said that between age and job satisfaction exists a statistically significant positive correlation $(\mathrm{P}<0.001)$. According to this relationship, with increased age is expected to increase the satisfaction felt by nurses to their profession (Table 2). 
Table 2. Univariate analysis

95\% Confidence

\begin{tabular}{llllll}
\hline & Mean & $\begin{array}{l}\text { Std. } \\
\text { Deviation }\end{array}$ & Lower & Upper & t-test \\
\hline Age-Job satisfaction & 37.760 & 7.935 & 35.505 & 40.015 & .000 \\
\hline $\begin{array}{l}\text { Education degree }- \text { job } \\
\text { satisfaction }\end{array}$ & -1.280 & 1.565 & -1.725 & -.835 & .000 \\
\hline $\begin{array}{l}\text { Psycho-social state }- \text { job } \\
\text { satisfaction }\end{array}$ & .480 & 1.054 & .780 & .180 & .002 \\
\hline
\end{tabular}

As about academic training and the job satisfaction was statistically significant, it is even negative type as $\mathrm{t}=-5782$ and $\mathrm{P}<0.001$, which means that if a nurse increases his academic education, level of professional satisfaction decreases. The relationship between nurse's psychosocial status and the level of job satisfaction, is significantly important, $\mathrm{p}=0.002$. So, a better psycho-social status, leads to higher job satisfaction.

Factors affecting the nurse's job satisfaction.

The most important intrinsic factor that affects the job satisfaction is "career growth" with an average of 3.84 scores, followed by "responsibility at work" with an average of 3.36. After them is ranked "equally treatment with colleagues" with an average of 3.22 .

Table.3 Intrinsic factors which affect nurse's job satisfaction

Table 4. Extrinsic factors which affect nurse's job satisfaction

\begin{tabular}{llll}
\hline Intrinsic factors & scores & Extrinsic factors & scores \\
\hline Career Growth & 3.84 & Monthly salary & 4.5 \\
\hline Responsibility at work & 3.36 & Working shift hours & 3.46 \\
\hline Equally treatment with colleagues & 3.22 & $\begin{array}{l}\text { Professional relationships with } \\
\text { physicians }\end{array}$ & 3.30 \\
\hline $\begin{array}{l}\text { The feeling of accomplishment in the } \\
\text { nursing profession }\end{array}$ & 3.1 & $\begin{array}{l}\text { Professional relationships with } \\
\text { co-workers }\end{array}$ & 3.22 \\
\hline Individual and professional promotion & 2.88 & Relationships with patients & 3.14 \\
\hline $\begin{array}{l}\text { Flexibility and independence, allowed } \\
\text { by the hospital administration }\end{array}$ & 2.72 & Overload in everyday duties & 3.04 \\
\hline $\begin{array}{l}\text { The possibility for continuous } \\
\text { professional training }\end{array}$ & 2.28 & $\begin{array}{l}\text { Rules and routines of the } \\
\text { institution }\end{array}$ & 2.90 \\
\hline & & Occupational Safety & 2.60 \\
\hline
\end{tabular}

The most important extrinsic factor that affects job satisfaction in the nursing profession is "the monthly payment", with an average of 4.5 scores, followed by “working shift hours” with 3.46 scores (Table 3, Table 4). 
Table 5. Correlation between intrinsic/extrinsic factors and age

95\% Confidence

\begin{tabular}{cccccc}
\hline & Mean & Std. Deviation & Lower & Upper & t-test \\
\hline $\begin{array}{c}\text { Intrinsic factor - } \\
\text { Age }\end{array}$ & -37.62286 & 8.68562 & -40.09128 & -35.15443 & .000 \\
\hline $\begin{array}{c}\text { Extrinsic factor - } \\
\text { Age }\end{array}$ & -37.54000 & 8.91004 & -40.07220 & -35.00780 & .000 \\
\hline
\end{tabular}

Assessment of extrinsic/intrinsic factors varies from one individual to another; however, it is thought that between age and factors influencing the job satisfaction, there is a significant correlation (Table 5). The sample t-test, by which it was estimated the relationship between affecting factors and the age of the interviewed nurses, has shown that this relationship is significant $(\mathrm{P}<0.001)$. In the lower ages the average factor scoring is higher. It is a negative correlation, which means that the job satisfaction of younger nurses is more dependent by affecting factors. Finally, it seems to have little difference between the averages of intrinsic and extrinsic factors. It was demonstrated that the difference between the averages of group factors that affect the nurse's job satisfaction is not significant ( $p=0.733)$.

\section{Discussion}

In our study resulted that the level of job satisfaction among the Vlora State Hospital's nurses was on average 2.92 points, approaching the neutral level. This is a relatively low level compared to the level found in similar studies, such as those conducted by Kristianstad University College (Wang Haijuan, 2006), which showed that in China, the level of satisfaction averaged 27.3 and in Sweden it was 4,06. Likewise, job satisfaction of nurses in Slovenian hospitals was at a medium level (Savič, 2012 ). Another study showed worse results with only $12.86 \%$ nurses were highly satisfied with their job and $37.14 \%$ were least satisfied with their jobs (Abida Sultana, 2011). A previous study in Albania (Gabrani Adriatik, 2014) concluded that nurses in public hospitals in Albania experience high level of overall job satisfaction and organizational commitment. But it has been conducted in the capital and nearby areas, where the quality of health services in notably higher comparing to regional hospitals.

In Albania, where the choice of professions is not free, but must be subject to competition, choice of profession as a nurse can be a random and forced alternative and not voluntary and desired. Based on this fact, nurses were asked how they chose to be nurses. $62 \%$ of them admit that they have chosen to be nurses because it was the better alternative they could obtained. $38 \%$ of them have chosen this profession willingly. The fact that only few of them have chosen voluntarily, shows that there isn't a desired profession. However this is a limited indicator, since in this paper are not collected data 
about the number of nursing students or the whys they've chosen their profession.

Monthly payments, as an extrinsic factor, are assessed by surveyed nurses as the most important influencing factor over nurse's job satisfaction. After processing the data, factor payments is ranked the first one with the highest average, by 4.5 scores, from 5 scores max. Even in the studies in the other countries the salary is ranked among the factors influencing job satisfaction (Kaddourah BT, 2013) (Savič, 2012 ), but they identify other more important factors. It is the very low level of wages in Albania, which keeps this factor in the first place.

Surveyed nurses in our study have provided information about their academic education, which showed that $56 \%$ of them had completed only First Study Cycle, 24\% were attending Second Study Cycle and 20\% had completed this cycle. According to data collected, were young nurses those who were attending or had completed Second Study Cycle, while elderly nursing had completed only First Study Cycle. These data demonstrate the new trend of young people who try to improve their professional education and to have continuous trainings. However, the level of nurses training in Albania is comparatively low; where nurses with Bachelor education occupied the largest proportion of staff (56\%). In a similar study, conducted in China and Sweden (Wang Haijuan, 2006) nurses holding bachelor degrees are the minority.

Many studies show that training or continuing education, develop at nurses the desire for higher positions, which consequently provide higher reputation. If these desires are not encountered, it leads to growing dissatisfaction for the existing nurse's role. In an experimental study (Ganzach, 2003) suggests that intelligence and education have differential effects on intrinsic job satisfaction and on pay satisfaction. Intelligence has a strong direct negative effect on intrinsic satisfaction but a negligible effect on pay satisfaction because it is positively associated with the level of desired job complexity but not with the level of expected pay. On the other hand, education has a strong direct negative effect on pay satisfaction but a small effect on intrinsic satisfaction because it is positively associated with expected pay. Researchers from Ethiopia (Agezegn Asegid, 2014) note that the growth in academic formation does not seem to have a positive effect on the nurse's job satisfaction. In contrast, studies conducted in other countries have noted that nurses with a higher education have been shown to be more satisfied with their job than those with lower education (Coomber B, 2007).

In our study was proved (with Sample t-test) that the relationship between academic training and the job satisfaction was statistically significant, and it is negative $(\mathrm{t}=-5782$ and $\mathrm{P}=0.001)$, which means that if the nurse has conducted and completed various cycles of academic study and 
its education is increased, then the level of satisfaction with the profession decreases. This may be related to the characteristics of employment in Albania, where the growth of the academic level does not lead automatically in increased responsibilities at work.

Like educational training, work experience as well seems to affect job satisfaction. Tzeng, in 2002, showed through his study (Tzeng HM, 2002) that the work experience as an individual factor, positively affects the job satisfaction. In this study resulted also that there is a positive correlation between age or work experience and job satisfaction, $(\mathrm{t}=33.65, \mathrm{P}<0.001)$. According to this finding, with ageing is expected to increase the satisfaction felt by nurses to their profession. So, there are young nurses whom don't have high levels of job satisfaction, perhaps because their expectations are not the ones provided by the nursing profession. This is a global trend, however, because even other studies (Sparks, 2012), (Leiter, 2010) confirm that Generation $\mathrm{X}$ nurses report more negative experiences than Baby Boomer in all measurements and that age is significantly related to job satisfaction, occupational commitment and intent to stay. (Wang, 2012)

Psycho-social situation of employees directly affects their expectations towards job, the way they perceive the conditions or situations, therefore influences the level of satisfaction at work. Usually people who pose problems in the family or in society, are characterized by frustration, and perform their role under the pressure of these problems; therefore they fail to enjoy the benefits that the profession offers to them, thus having a low level of job satisfaction. Based on the theory of the impact of individual characteristics on job satisfaction (David Watson, 1988), we put on the questionnaire the question "How would you describe your psycho-social state?”, which had four possible answers. It is noted that 56\% feel "neutral" while $44 \%$ say that their psycho-social is somewhat good. The average of this situation is $\mathrm{x}=2.44$, therefore psycho-social situation varies between "neutral" and "somewhat good". The statistical evaluation of the relationship between nurse's psychosocial status and the job satisfaction showed that it is statistically significant. So, the much better is his psycho-social situation, the higher is the nurse's commitment to the job. There are several studies that show a positive correlation between positive emotions and job satisfaction (Gurková, 2012) (Agezegn Asegid, 2014). While other authors (Ann Adams, 2000) have shown that individual nurse characteristics were found not to be associated with job satisfaction.

At the end of the survey, nurses were asked if they wish to change the profession, taking into account the fact that nowadays the number of nurses who willingly abandon their profession is increasing. According to the results of this question, only $28 \%$ of respondents were satisfied with their profession and didn't want to change it, $14 \%$ of nurses were looking for 
another profession, which means that they appear unhappy with this profession and 58\% of respondents said they are eager to change profession, but cannot due to various factors such as their age, lack of other opportunities, family income, etc. Numerous articles have raised the problem of nurses who are choosing not to practice or to leave the profession (Ahmad H. Abu Raddaha, 2012) (Lintern, 2013)(Mervi Flinkman, 2013).

\section{Conclusion}

In conclusion, we can say that the level of job satisfaction among nurses involved in this study is below average. This relatively low level of satisfaction seems to be affected by several factors, like the fact that job salary is low, keeping present the job difficulty, and difficulties in career promotion or forced choice of profession. Less satisfied groups in nursing profession are young people and high educated nurses. The low level of professional gratifying is expressed as well in the fact that over $70 \%$ of nurses in the study would like to practice another profession.

Increasing the level of satisfaction at work is not only of interest to nurse, but all the staff, the institution and the patient. Hospital administration needs to continuously monitor the level of staff professional pleasure and take measures to modify the contributing factors.

\section{References:}

Abida Sultana, R. R. (2011). Level of job satisfaction among nurses working in tertiary care hospitals of Rawalpindi. Rawal Medical Journal , 36(2): 150154.

Agezegn Asegid, T. B. (2014). Factors Influencing Job Satisfaction and Anticipated Turnover among Nurses in Sidama Zone Public Health Facilities, South Ethiopia. Nursing Research and Practice , Article ID 909768, 26 pages.

Ahmad H. Abu Raddaha, J. A. (2012). Jordanian nurses' job satisfaction and intention to quit. Leadership in Health Services , 25(3):216-231. DOI: 10.1108/17511871211247651.

Al-Aameri, A. S. ( 2000). Job satisfaction and organizational commitment for nurses. Saudi Medical Journal , Vol. 21 (6): 531-535.

Ann Adams, S. B. (2000). Hospital nurses' job satisfaction, individual and organizational characteristics. Journal of Advanced Nursing , 32(3):536 543. DOI: 10.1046/j.1365-2648.2000.01513.x.

Anthony P. Carnevale, N. S. (2012). Healthcare. Georgetown Policy Public Institute .

Coomber B, B. K. ( 2007). Impact of job satisfaction components on intent to leave and turnover for hospital-based nurses: a review of the research literature. Int J Nurs Stud. , Feb; 44(2):297-314. 
David Watson, L. A. (1988). Development and Validation of Brief Measures of Positive and Negative Affect: The PANAS Scales. Journal of Personality and Social Psychology, Vol. 54. No. 6, 1063-1070.

Gabrani Adriatik, H. A. (2014). Perceived organizational commitment and job satisfaction among nurses in Albanian public hospitals: A cross-sectional study. International Journal of Healthcare Management , DOI: http://dx.doi.org/10.1179/2047971915Y.0000000019.

Ganzach, Y. (2003). Intelligence, Education, and Facets of Job Satisfaction. Work and Occupations , 30(1):97-122. DOI: 10.1177/0730888402239328.

Gurková, E. Č. (2012). Job satisfaction and emotional subjective well-being among Slovak nurses. International Nursing Review , 59: 94-100. doi: 10.1111/j.1466-7657.2011.00922.x.

Herzberg Frederick, M. B. (1959). The Motivation to Work (2nd ed.). New York: John Wiley. ISBN 0471373893.

Kaddourah BT, K. A.-S.-T. (2013). Factors impacting job satisfaction among nurses from a tertiary care centre. J Clin Nurs. , 22(21-22):3153-9. doi: 10.1111/jocn.12261. Epub 2013 Jun 20.

Knoopa, R. (2010). Relationships Among Job Involvement, Job Satisfaction, and Organizational Commitment for Nurses. The Journal of Psychology: Interdisciplinary and Applied, Volume 129, Issue 6, 1995 , pg.643-649, DOI:10.1080/00223980.1995.9914935.

Leiter, M. P. (2010). Generational differences in distress, attitudes and incivility among nurses. Journal of Nursing Management, , 18: 970-980. doi: 10.1111/j.1365-2834.2010.01168.x.

Lintern, S. (2013). Exclusive: Numbers choosing to leave nursing rise by 26\%. Nursing Times.net , http://www.nursingtimes.net/nursingpractice/specialisms/management/exclusive-numbers-choosing-to-leavenursing-rise-by-26/5065685.article.

Lu H, W. A. (2005). Job satisfaction among nurses: a literature review. Int J Nurs Stud. , Feb;42(2):211-27.

Mathew. (2015). What is the job satisfaction for nurses? http://healthcareers.yoexpert.com/health-career-profiles-11525/what-is-the-job-

satisfaction-for-nurses-37119.html.

Mervi Flinkman, U. I.-B. (2013). Young Registered Nurses' Intention to Leave the Profession and Professional Turnover in Early Career: A Qualitative Case Study. ISRN Nurs. , 2013: 916061.

Mrayyan, M. T. (2005). Nurse job satisfaction and retention: comparing public to private hospitals in Jordan. Journal of Nursing Management, , 13: 40-50. doi: 10.1111/j.1365-2834.2004.00453.x.

Mueller CW, M. J. (1990). Nurses' job satisfaction: a proposed measure. Nurs Res. , Mar-Apr;39(2):113-7. 
Savič, M. L. (2012 ). Job satisfaction of nurses and identifying factors of job satisfaction in Slovenian Hospitals. Croat Med J. , Jun; 53(3): 263-270.

Sparks, A. M. (2012). Psychological empowerment and job satisfaction between Baby Boomer and Generation X nurses. Journal of Nursing Management , 20: 451-460. doi: 10.1111/j.1365-2834.2011.01282.x.

Tzeng HM. (2002). The influence of nurses' working motivation and job satisfaction on intention to quit: an empirical investigation in Taiwan. Int $J$ Nurs Stud. , 39(8):867-78.

Wang Haijuan, N. Y. (2006). Main factors influencin nurse job sadisfaction. Kristianstad University College.

Wang, L. T. (2012). Job satisfaction, occupational commitment and intent to stay among Chinese nurses: a cross-sectional questionnaire survey. Journal of Advanced Nursing , 68: 539-549. doi: 10.1111/j.1365-2648.2011.05755.x. 